\title{
Joaquín Capelo: Comisionado Especial del Supremo Gobierno y Prefecto del Departamento de Loreto (1899-1900)
}

\section{Joaquín Capelo: Special Commissioner of the Supreme Government and Prefect of the Department of Loreto (1899-1900)}

\author{
Ana Esther Laya Alcedo \\ Universidad Nacional Mayor de San Marcos \\ ana.151192@gmail.com
}

\section{RESUMEN}

En este trabajo se busca analizar la obra estatal en pos del desarrollo de infraestructura, fomento de actividades económicas y sociales en Loreto entre 1899 y 1900, durante la llamada República Aristocrática. A fin de estudiar este tipo de modernización material y social, nos concentramos en la figura y gestión de Joaquín Capelo, Comisionado Especial del Supremo Gobierno de Eduardo López de Romaña y Prefecto en el departamento de Loreto, como alguien que representa el ascenso de un nuevo tipo de funcionario y una nueva forma de administración y gestión pública. El presente artículo toma como enfoque la historia política, pues se describen y analizan las políticas de Estado dentro de los proyectos modernizadores dirigidos a Loreto. Palabras claves: Joaquín Capelo; territorio; nacionalización; políticas; modernización.

\section{ABSTRACT}

This paper seeks to analyze the state work in pursuit of the development of infrastructure, promotion of economic and social activities in Loreto between 1899 and 1900, at a crucial period in our history: the Aris-tocratic Republic. In order to study this type of material and social modernization we concentrate on the figure and management of Joaquín Capelo, Special Commissioner of the Supreme Government of Eduardo López de Romaña and Prefect in the Department of Loreto as someone who represents the rise of a new type of official and a new form of public administration and management. This article is addressed from political history, because it describes and analyzes state policies within the modernizing projects addressed to Loreto. Keywords: Joaquín Capelo; territory; nationalization; policy; modernization. 


\section{Introducción}

Este artículo se aborda desde la historia política, pues se describe y analizan las políticas de Estado implementadas en Loreto en el tránsito de 1899 a 1900, dentro de la gestión de Joaquín Capelo como delegado del gobierno en dicho departamento en una situación de crisis interna. Se debe tomar en cuenta que las políticas implementadas por el Estado peruano en el siglo XIX tenían soporte legal, institucional, territorial y económico, es decir que estaban reglamentadas, y se llevaban a cabo de acuerdo a las competencias de los ministerios, dirigidos a los departamentos de acuerdo los intereses proyectados en ellos y se sostenían en base a un presupuesto.

A diferencia de lo que ocurre actualmente con las llamadas políticas públicas, las cuales implican el consenso entre Estado y sociedad, el con sentido público (Aguilar Villanueva, 1992, p. 30), en esta época se trata de políticas de Estado influidas por las necesidades de la clase política dominante, que controla y regula el accionar de los gobiernos. Otra divergencia es la acotación de acciones y funciones que se llevan a cabo. En las políticas públicas se focaliza por institución y campo de acción, en cambio en las políticas de Estado una sola institución, e incluso la persona que la representa en un determinado lugar, puede estar investido de varias atribuciones, con lo cual interviene en actividades administrativas, económicas, comerciales, de defensa, etc.

Considérese que las políticas de Estado a diferencia de las políticas de gobierno, responden a planes que se proyectan a lo largo de varios gobiernos. Pueden ser prioridad en algunos, en otros no, pero se mantiene vigente y escapa a las tiendas políticas que tienen el poder en el periodo que se estudia. Para el caso de Loreto es importante conocer su relación con el Estado peruano a fines del siglo XIX, cómo se administraba el departamento, sus carencias y necesidades, la proyección de la modernización hacia esta región, etc. Por eso empezaremos a partir de esta parte la descripción y análisis del contexto en que se enmarca la gestión de Joaquín Capelo en Loreto.

A fines del siglo XIX, durante la llamada República Aristocrática, el Estado Peruano estaba preocupado por la modernización del territorio bajo su jurisdicción en el afán por convertirse en un país desarrollado a la manera de sus pares en Europa y Estados Unidos. Aunque no se trataba de una modernización que implicara cambios de fondo en la sociedad peruana, sino de forma en el paisaje urbano y rural, se contaba con varios obstáculos por superar. Uno de ellos era que no todos los lugares del Perú se hallaban nacionalizados, es decir la presencia del Estado Peruano era muy débil. A esto se sumaba la falta de una delimitación de fronteras clara con los países vecinos que hacía renacer el temor de la guerra y la pérdida de territorio.

El departamento de Loreto era el lugar que cumplía precisamente con las condiciones que preocupaban al Estado Peruano, por ello estuvo en su punto de mira durante la época mencionada. Lograr la nacionalización de Loreto en la república implicaba llevar hacia ella el proyecto de modernización y asimilarla en la administración peruana, aunque se tuviera que otorgar algunas excepcionalidades.

La punta de lanza del proyecto de modernización del Estado Peruano fue el Ministerio de Fomento y Obras Públicas creado en 1896. Desde él se gestionaron una serie de políticas para la mejor administración del Perú en cuanto a desarrollo de infraestructuras, de actividades económicas y sociales (Quiñones, 2012, p. 21). Siguiendo a Harold Laski, se establecen dos aspectos del Poder Ejecutivo de un Estado: el político y el administrativo. El primero propone políticas de Estado, las cuales son debatidas y aprobadas para que el segundo las ejecute (Laski en Quiñones, 2012, pp. 1-2). En ese sentido el Ministerio de Fomento y Obras Públicas, se encargaba de la ejecución de las políticas, junto con los demás ministerios en sus respectivos asuntos. Antes de 
la creación de este ministerio, dichos rubros estaban distribuidos en los ministerios de Gobierno y Policía, Hacienda y Comercio, y Justicia, Culto, Instrucción y Beneficencia (Quiñones, 2012, p. 13). El Ministerio de Fomento y Obras Públicas respondió a la evolución de la administración pública peruana durante la república, pues asumía las funciones de rubros que hasta entonces no habían sido atendidos con mucho énfasis.

Loreto carecía en primer lugar de vías de transporte que permitieran la comunicación más rápida con la capital. En segundo lugar, obras de infraestructura para el progreso material de la zona. En tercer lugar, que la administración pública resultara eficiente en la región, y, cuarto lugar que las actividades económicas beneficiaran tanto al tesoro loretano como al nacional. Se suponía que esto tendría que ser gestionado por el prefecto, máxima autoridad del departamento, y el gobierno central. Sin embargo, en Loreto la situación política se encontraba tensa por la frustrada proclamación del Estado Federal y por posteriores actos de corrupción en los que estaban involucrado el prefecto Emilio Vizcarra, funcionarios y figuras importantes de la región (Barclay, 2009, p. 397). Por ello se vio necesario enviar a un Comisionado Especial del Supremo Gobierno, representante del gobierno central al que se le envestía de poderes para negociar y tomar decisiones en su nombre. El enviado fue Rafael Quirós, ex ministro de Hacienda de Morales Bermúdez (p. 398).

Al inicio convivieron la figura del prefecto y comisionado especial, pero luego Quirós tomó la decisión de fusionarlos dada la agudización de la crisis política en Loreto. Es en este panorama que aparece Joaquín Capelo, quien antes de asumir dichos cargos se había desempeñado como Director de Fomento en el Ministerio de Fomento y Obras Públicas (Quiñones, 2012, p. 37), además fue gestor de la llamada Vía Central del Perú que comunicaba a Lima y Loreto por vía terrestre y fluvial. Capelo desempeñó el cargo de Comisionado Especial de noviembre de 1899 a abril de 1900, aunque se trató de un corto periodo, en este pudo hacer gestiones que tuvieron que ver mucho con el ámbito de trabajo del Ministerio de Fomento y Obras Públicas, pues implicaban la gestión de los terrenos de montaña, la demarcación territorial, el establecimiento de la estadística, regulación del correo, etc. (Espinoza, 2016, p. 266). Además tuvo el rol de pacificador en la crisis política que se estaba viviendo en el departamento al tomar acciones que la estabilizaron. También tuvo desaciertos como todos los funcionarios públicos, siendo el más notable el establecimiento de un muelle de metal a cargo del concesionario Georg von Hassel, cuyo contrato trajo serios problemas a los comerciantes de Iquitos como se consigna en una publicación que se presentó al gobierno en 1900 llamada El comercio de Loreto. Representación del comercio de Loreto sobre las tarifas de carga, descarga y muellaje, impuestas por el doctor Joaquín Capelo, comisionado especial del Supremo Gobierno.

Si bien las políticas impulsadas en la gestión de Capelo no fueron de gran envergadura, se propone en este artículo que coadyuvaron a la modernización de Loreto sobre todo a nivel administrativo. Aunque también propuso algunas medidas a nivel social como la instalación de un centro de instrucción media en Iquitos y dispuso que se ofreciera garantías a los trabajadores en las haciendas gomeras (Espinoza, 2016), estas no se verían cumplidas durante su gestión, sin embargo se puede considerar que Capelo por lo menos planteó la necesidad de estas medidas.

El papel que cumplía Capelo revelaba el ascenso de un nuevo tipo de funcionario y nueva forma de administración, pues al ser ingeniero civil con experiencia en el Estado contaba con el bagaje intelectual y profesional de alguien que conoce a fondo los problemas y necesidades que hay en el quehacer burocrático, asimismo si revisamos la línea de carrera de las autoridades que estaban al frente de direcciones, secciones u oficinas que tuvieran que ver con el fomento de la modernización, notaremos que se trata en su mayoría de personas que seguían las ciencias 
aplicadas como ingenieros o médicos. Aunque debemos tomar en cuenta que personajes como Capelo conviven con lo que señala Augusto Ruiz fue «una modernización sin modernidad» (Ruiz, 1994, p. 25) pues produjo un progreso limitado a la luz de la modernidad interpretada por las necesidades de la clase dominante (Ruiz en Quiñones 2012, p. 6) y se encuentran en un tránsito entre lo nuevo y lo viejo, poniendo las bases de lo que será la modernización de bien entrado el siglo XX.

En este trabajo se está de acuerdo con José Ignacio López Soria respecto al tipo de modernidad que experimentó en nuestro país durante el siglo XIX, el discurso de bienestar, el cual «fue portador de una racionalidad que se orienta a propiciar el desarrollo nacional por la vía de la exploración y explotación de los recursos nacionales y su incorporación al circuito internacional de la mercancía» (2007, p. 33). Este discurso estimuló el interés por la articulación y el dominio de las actividades productivas (p. 36).

\section{Antecedentes}

Loreto por su situación de territorio de frontera (Santos Granero y Barclay, 2002), había tenido una condición singular en el siglo XIX, respecto a sus pares en el país, pues por buen tiempo en este departamento se gozó de una excepcionalidad de cobro de algunos impuestos, a través de la contribución personal. Esto debido a que a ella se dirigían parte de los proyectos de colonización europea y el comercio con el Atlántico a través del río Amazonas. La comunicación entre Loreto y Lima tardaba muchos días en ser efectiva a causa de la falta de carreteras, y la población que estaba asentada allí era pequeña, donde se encontraban comerciantes nacionales y extranjeros. Estos comerciantes tenían fuerte injerencia en las decisiones más transcendentales que se tomaban en la región, en algunos casos ocupaban cargos públicos o simplemente eran personas notables en Loreto. Tenían el poder para desestimar o anular alguna reforma que no estuviera acorde con sus intereses, ya sea en cuanto a acceso de mano de obra, rutas para la navegación o los aranceles de importación y exportación. Por esta situación, la presencia del gobierno peruano era tenue, pues debía ponderar los intereses de la región con los del país (Barclay 2009, p. 64), llevando a que el proceso de nacionalización de la Amazonía tuviera avances y tropiezos.

Tras la Guerra con Chile, el Estado peruano prestó una especial atención hacia Loreto pues se avizoraba en ella una fuente de riquezas que en el pensamiento de la época eran inagotables, y que traería la bonanza económica como lo había hecho el guano y el salitre. Sin embargo, la lejanía y la poca fuerza del gobierno en Loreto, hacían que se asomara el miedo de que este departamento se convirtiera en otra Tarapacá. (Barclay, 2009, p. 115). Por ello cuando se aplicaron reformas para el país como la descentralización fiscal y la creación de las Juntas Departamentales, se trató de hacer conciliar los intereses del Estado y de los comerciantes locales. Sin embargo, no todo resultó como se esperaba, pues no todas las autoridades de la región tomaron en cuenta esta precaución, y por aspiraciones personales o políticas mermaron la autonomía de Loreto. Esto terminó en la proclamación del Estado Federal de Loreto en 1896.

La proclamación del Estado Federal de Loreto se dio en base a la propuesta federalista que había hecho en campaña Nicolás de Piérola. Pero una vez que asumió el gobierno, no puso en marcha esta propuesta, y se pensó que se trataba de un intento separatista, tal como temían que ocurriera tiempo antes (Barclay, 2009, p. 300). Aunque dicho evento no contó el apoyo de la población local, se enviaron fuerzas militares para aplacarlo y se nombraron personas que entonces se consideraban de confianza para el gobierno, como el coronel Emilio Vizcarra. Esto no bastó para que la región se estabilizara.

Para hacer más fuerte la posición del gobierno peruano en Loreto, el Congreso aprobó enviar a Rafael Quirós en una Comisión Especial en 1897 (Barclay, 2009, p. 397), que tenía sus 
antecedentes en 1886 cuando se mandó una Comisión Informadora y una Comisión Especial en 1890 que debían dar cuenta de la situación de Loreto a nivel político, económico y social. La Comisión Informadora contó con dos presidentes, el primero fue Federico Alzamora, excomandante del Apostadero de Loreto, y el segundo fue Melitón Carvajal, marino peruano, ambos tenían referencias desactualizadas del departamento, por lo que las recomendaciones que hicieron al gobierno no estaban del todo acorde con la realidad de Loreto (p. 126). La Comisión Especial de 1890 estuvo presidida por el coronel Samuel Palacios Mendiburu, quien fue prefecto y comandante del departamento ese mismo año y en 1891. Palacios Mendiburu al comprender mejor la realidad loretana, propuso que la capital del departamento fuera Caballococha, aunque esto no llegó a llevarse a cabo.

Ambos antecedentes se toparon con el departamento de Loreto en relativa calma. A pesar que seguían las disputas de funcionarios públicos por el control de la región a nivel político y económico, esto no se comparaba a lo que era el panorama de Loreto en 1897. Rafael Quirós se encontró con una situación tensa, pues no hacía mucho que la capital había cambiado de Moyobamba a Iquitos, lo que acrecentó los conflictos entre las élites de las dos ciudades y tuvo que competir en el poder Emilio Vizcarra, quien había sido nombrado prefecto un año antes.

El coronel Emilio Vizcarra era un personaje controvertido en Loreto. No exento de habilidades políticas, había sido nombrado prefecto de Loreto en diversas ocasiones y se encargó de reestablecer el orden en momentos de crisis desde su condición de Jefe de la gendarmería. Vizcarra, originario de Arequipa, poseía un fundo agrícola cerca de Iquitos (Paucarpata), un fundo gomero y puesto comercial en el Yavarí, además de una lancha para el comercio. Había amasado una cierta fortuna gracias a su uso indiscriminado de recursos públicos, mano de obra indígena y el trabajo de los gendarmes (Barclay, 2009, p. 302). Quirós depuso a Vizcarra tras haberle encontrado un caso de corrupción, reunir testigos y mandar un informe al gobierno que decía lo siguiente:

El Comisionado Especial del Supremo Gobierno en Loreto ha manifestado la conveniencia de que Emilio Vizcarra haga renuncia de su cargo de Prefecto de Loreto, aduciendo que por motivos de negocios particulares de Vizcarra en el departamento, por sus relaciones y por otras causas de ese orden su influencia se ha gastado al extremo de ser hecho probado su impopularidad (AGN, Archivo Republicano, Fomento, Expediente del Comisionado Especial del Supremo Gobierno en el Departamento de Loreto. Rafael Quirós. Iquitos, 14 de enero de 1898. $\left.\mathrm{n}^{\circ} 57, \mathrm{pp} .1-2\right)$.

Fue así que ejerció de Comisionado Especial y Prefecto a la vez. Esta dualidad de funciones fue lo que le tocó a su sucesor, Joaquín Capelo. En las siguientes líneas se explicarán las políticas impulsadas durante la gestión de Capelo, basadas en el Registro Oficial del Departamento de Loreto. Administración del Comisionado Especial del Supremo Gobierno Sr. Dr. Joaquín Capelo (1900).

\section{Nombramiento de personal y atribuciones administrativas}

Cuando Joaquín Capelo llegó a Iquitos, lo primero que hizo fue encargarse de la designación de nuevo personal en los cargos de la prefectura y subprefectura, nombrar autoridades fluviales, personal en las lanchas, en la caja fiscal, en las aduanillas, en la aduana de Iquitos, pues, según su criterio, se habían puesto en algunos casos a personas que no cumplían con las competencias para asumir los cargos. Entre los puestos importantes nombró como Ayudante de la Prefectura a Ernesto A. Rivas; como Oficial Archivero y de Partes de la Secretaría de la Prefectura a Pedro Nájar; como Subprefecto del Bajo Amazonas a Francisco Carrera y Raygada; como Secretario Amanuense de la Subprefectura de 
Alto Amazonas a Alfredo Cáceres; como Subprefecto de San Martín a Gregorio Estevan Salmón; como Secretario Amanuense de la Subprefectura de Moyobamba a José R. Pinedo; y como Cajero Fiscal del Departamento nombró al Coronel Juan Fajardo (Capelo, 1900, pp. 6-7)

Respecto a las autoridades fluviales, creó la Capitanía de Puerto en Yurimaguas y la Capitanía de Puerto en Contamana con la intención de regular el tráfico de las embarcaciones en el río Huallaga y establecer el resguardo aduanero en dichas regiones fluviales. Para ello nombró a Francisco G. Zapatero para la primera y a Alfredo Gutierrez para la segunda (Capelo, 1900, p. 8). Después de dichos nombramientos creó la aduanilla de frontera en el Yurúa con Estanislao Castañeda a su cargo y la ampliación de atribuciones del agente aduanero en la aduanilla de Leticia, nombrándose para tal efecto a José A. Cabieses, para que pueda tener supervigilancia y llevar el control del servicio fluvial aduanero (p. 9). La creación de las capitanías de puerto y la aduanilla permitía mayor control sobre los impuestos de la aduana que desde su creación había generado mayores ingresos a la región. Sin embargo, se tenía en cuenta que muchas veces se usaba vales que no llegaban a ser saldados con dinero en efectivo, lo cual causaba una irregularidad en la aduana.

El comisionado especial amplió también las facultades del teniente gobernador del pueblo de San Fernando en el río Yavarí. Con tal fin nombró al teniente gobernador Pedro Ramos, sin tener que dejar el cargo que en ese entonces ejercía. Como comisario fluvial debía mantenerse en contacto con el capitán de Palmela y el capitán de Leticia, adoptando sus disposiciones. Autorizó el despacho de mercadería de importación en Leticia, Palmela y Caballococha, traída en vapores desde el exterior (Espinoza, 2016, p. 266).

En tanto, en Leticia, creyó conveniente fomentar la formación de un centro urbano, donde ya existía una dependencia aduanera de la principal en este puerto, para ello dispuso:

$1^{\circ}$ Autorizar la formación de un pueblo en Leticia y dar al efecto terreno gratis para la construcción de casas en esa zona hasta un kilómetro en cualquier sentido del edificio en construcción destinado a la dependencia aduanera de ese puerto;

$2^{\circ}$ El Jefe de esa dependencia aduanera y Comisario del Yavarí, queda autorizado para hacer el trazo de la población y dar los lotes de terreno urbano que se soliciten con cargo de que sea hecha la construcción dentro del plazo máximo de un año, quedando el lote cercado dentro de los primeros seis meses y quedando expresamente reiterado lo que prescribe al respecto la ley y decreto reglamentario sobre terrenos de montaña, y lo que no puede ser adjudicado (Capelo, 1900, p. 25).

\section{Pacificación de la región}

A partir del 20 de noviembre de 1899 hubo que pedir refuerzos a Lima para llevar a cabo la campaña militar sobre Moyobamba, con el fin de acabar con el movimiento de insurgentes que estaba liderado por el coronel Emilio Vizcarra, quien junto a sus hombres tenía tomada buena parte de la provincia de San Martín y que declaraban la independencia de la misma. Para hacerles frente, Capelo encomendó al teniente coronel Teobaldo Gonzales la campaña militar y gestionó la ayuda del gobierno pidiendo víveres, hombres y embarcaciones fluviales como la lancha Yurimaguas y el vapor Castilla.

Se dio un combate en el pueblo de Tabalosos, en la provincia de Lamas, el 11 de enero de 1900, desde las 3pm. hasta las 6pm., en que las fuerzas al mando de Gonzales dieron ofensiva a las fuerzas de Vizcarra, finalizando con 3 heridos y 3 prisioneros del bando de este último. Para ese entonces todavía no se tenía una ventaja sobre los rebeldes que pudiera garantizar la victoria del gobierno, sin embargo, el ánimo de la población, a decir de Gonzales, estaba con 
ellos (Capelo, 1900, p. 37). Mientras tanto, Capelo en la correspondencia que enviaba a Gonzales le daba instrucciones de cómo debía dirigir sus fuerzas, le indicaba el apoyo de embarcaciones como Unión y Amelia, los posibles movimientos de Vizcarra y la situación en que se encontraba la seguridad en Iquitos.

El 26 de febrero de 1900, Gonzales informaba, por correspondencia a Capelo, del triunfo de sus fuerzas sobre los rebeldes, la captura del jefe de Los Malcriados, el sargento mayor Goyzueta, la dispersión de sus allegados, la persecución y la caída mortal de Vizcarra. Para las 5pm. de ese día era dueño de la plaza de Moyobamba, con el haber de nueve muertos, entre los que se incluía Vizcarra, heridos Goyzueta y cuatro soldados más, y 11 prisioneros. (Capelo, 1900, p. 47). Gonzales mencionaba que aún quedaban rebeldes en el río Negro y Pucatambo, y que se encargaría de reducirlos en caso no se rindieran.

En un segundo parte, declara que los rebeldes restantes se rindieron y solicitaron únicamente su libertad, algo que Gonzales les concedió por no considerarlos de gran importancia. Después, hizo lo mismo con parte de los prisioneros que ya tenía en su poder, quedándose con los cabecillas. Además, manifestó que el sentir del pueblo de Moyobamba era del retorno de la paz y tranquilidad, pues en la resistencia se involucraron hombres, mujeres y niños.

En una tercera parte, explica nuevamente y de manera más detallada, como había sido la reducción de las fuerzas de Vizcarra, caído mortalmente por un disparo en el pecho, la rendición de sus allegados, la captura de los prisioneros y la petición de libertad que pedían. Asimismo refirió que encontró la municipalidad y la subprefectura en muy malas condiciones, con un deplorable estado de su caja. Resaltó que los profesores de la Instrucción Pública continuaron haciendo sus labores manteniendo su independencia respecto a los rebeldes. Por último, había documentación perteneciente al coronel Vizcarra que remitiría al comisionado próximamente (Capelo, 1900, p. 49).

La ofensiva enviada por Capelo ayudó a calmar la tensión que se vivía en Loreto desde hacía algunos años. Tras haberse dejado al descubierto los malos manejos de Vizcarra en la prefectura, éste aprovechó el cambio de capital de Moyobamba a Iquitos para escapar del control del comisionado especial. Hay que tomar también en cuenta que la élite moyobambina se sentía descontenta por la pérdida del estatus de su ciudad como la principal del departamento, lo que seguramente se sumó al apoyo a Vizcarra, quien veía la oportunidad de recuperar su poder e influencia para continuar con sus negocios. Más, al no haber apoyo popular no prosperó el movimiento y fue aplacado por las fuerzas militares. Capelo en sus misivas con el teniente Gonzales habla de la pacificación de la región y del enjuiciamiento que seguiría a los rebeldes, pero era consciente que esto no era suficiente para solucionar la situación de Moyobamba y de Loreto en general, por ello estuvo de acuerdo con la amnistía de varios prisioneros. La importancia de esta pacificación fue que mostró la necesidad de dar atención a ciudades como Moyobamba, que contaban con numerosa población y que históricamente habían sido sede administrativa y eje de comercio, lo que las hacía puntos clave para mantener la estabilidad en Loreto. Aunque Capelo no estuvo allí, dado su corto periodo como prefecto, dejó testimonio de una situación de la que habrían de estar pendiente sus sucesores en el cargo.

\section{Administración del territorio}

Otro asunto del que tomó parte el comisionado especial fue el de terrenos de montañas, al hacer notar que se estaba expidiendo títulos de propiedad de manera irregular, sin seguir la reglamentación de 1899 a personas que no estaban registradas, ni ante la prefectura ni el gobierno. Mediante una carta al director 
de Fomento, Capelo se queja de esta situación insistiendo en que sólo correspondía al Ministerio de Fomento tratar la cuestión de los terrenos de montaña y que no se estaba beneficiando al Estado, pues se estaba otorgando más de mil hectáreas, que era el límite de lo que se podía entregar a una persona (Capelo, 1900, pp. 70-71). Ante esto Capelo, para facilitar la tramitación y establecer el imperio de la ley, adoptó dos medidas: $1^{\circ}$ Aceptar el precio de cinco soles por hectárea, es decir el mínimo por ley, y $2^{\circ}$ Las solicitudes serán tramitadas por la prefectura para elevarlas a la Dirección de Fomento, que decidiría si eran otorgables o no los terrenos.

La Dirección de Fomento estuvo de acuerdo con Capelo, considerando que la dirección era la única encargada de ver el asunto de terrenos de montaña. Además, Capelo dio a conocer un decreto sobre la explotación de gomales, del cual se resaltan los siguientes artículos:

Art $3^{\circ}$ Para la explotación de los terrenos de gomales, es necesario abonar en la Tesorería Fiscal un derecho de dos soles por estrada en cada año, y hallarse inscrito el interesado en el registro que se llevará al efecto en la misma Tesorería Fiscal como arrendatario de dichos gomales, para lo cual le bastará presentar, acompañando el recibo de inscripción, un recurso por duplicado ante la Prefectura, especificando la extensión aproximada del lote, su distancia a la población más cercana dada en kilómetros o en horas de navegación a vapor o en canoa, de bajada o de surcada, y todos los demás detalles conducentes a fijar la ubicación de los terrenos, a cuyo efecto adjuntará un croquis, también por duplicado, el que podrá ser hecho por el mismo interesado.

Art. $6^{\circ}$ La Tesorería Fiscal abrirá una cuenta especial bajo la denominación de terrenos de montaña a la que abonará todos los ingresos que se obtengan conforme a esta resolución y las de su referencia; cargando a esa cuenta los gastos que se hagan para la recaudación, publicaciones y demás autorizadas por la ley, y el saldo que resulte de dicha cuenta al vencimiento de cada año, se aplicará íntegramente a la construcción de los caminos del Departamento en este orden. El cincuenta por ciento para los siguientes caminos:

Terminación y perfeccionamiento del camino de Yurimaguas a Moyobamba, abierto por el ingeniero Carlos Pérez en cumplimiento de una ley;

Regularización del camino antiguo existente entre los mismos puntos, Yurimaguas y Moyobamba; y

Apertura del camino entre Tarapoto y el pongo de la quebrada de Cainarache, para empalmar con el que sigue por las orillas de ese río hasta el Huallaga y Yurimaguas.

El cincuenta por ciento restante se aplicará al establecimiento de comunicación regular por los varaderos que conducen a los ríos Yurúa y Purus y los que existen para el Putumayo y el Napo a fin de establecer comunicación directa por dentro del propio territorio con sus límites (Capelo, 1900, pp. 75-76).

Como se observa en esos artículos, la preocupación del comisionado especial por la mejora de los caminos era indispensable para su gestión, por ello su insistencia en que los trámites de los terrenos de montaña pasasen por el despacho de la prefectura. De este modo, el gobierno se beneficia con la recaudación del dinero de los interesados en obtener los terrenos. Además, la apropiación de los terrenos por parte de individuo no podía pasar por el territorio determinado para las ciudades, en especial Iquitos, en donde se encontraban las principales instituciones, ni tampoco por las vías y caídas de agua, minas, yacimientos o lavaderos, pues estas quedaban en propiedad del Estado.

De otra parte, también se atendió la cuestión del plano de Iquitos, tomando en cuenta el expediente iniciado en mayo de 1893 por el Alcalde del Consejo Provincial de Iquitos en que 
se solicitaba que «el área de la ciudad de Iquitos sea encerrada en una figura cuadrangular formada sobre la margen izquierda del río Amazonas por esta margen y tres líneas trazadas a mil quinientos metros de distancia de la Iglesia Matriz, una en dirección norte y las otras dos en dirección sur y a uno y otro lado de la Matriz, visto el plano formado por el Capitán de Navío Enrique Espinar y los informes de este y del ingeniero Carlos Pérez» (Capelo, 1900, p. 77). Fue así que el despacho del comisionado especial resolvió aceptar esta solicitud y que se haga extensiva a otras poblaciones donde haya municipalidades de distrito en el departamento de Loreto. Asimismo, el municipio se haría cargo de hacer las gestiones con el Ministerio de Fomento para resolver la otorgación de terrenos a particulares que ya se había hecho antes de la aprobación del plano para fijar las ventas y cobros.

\section{El correo central y el muelle de Iquitos}

Además de su intervención en el asunto de terrenos de montaña, Capelo atendió la cuestión del Correo Central, disponiendo que el servicio regular de correos con la capital se restablezca por la Vía Central, distribuyéndose en dos secciones: entre Masisea y Puerto Bermúdez y entre Masisea e Iquitos, destinando para la primera la lancha Pizarro y para la segunda las lanchas Cahuapanas y Amazonas. (Capelo, 1900, pp. 95-97). Más adelante mandó a cambiar el itinerario del correo central, considerando que se podía ahorrar el tiempo de espera de los pasajeros y la carga en Masisea para abordar la lancha Pizarro, disponiendo:

$1^{\circ}$ Que en lo sucesivo los correos que salgan de Iquitos por la Vía Central y que atenderán las lanchas "Amazonas", "Cahuapanas" " "Iquitos", sean solo tres en cada mes, debiendo despacharse de este puerto los días 1,10 y 20, respectivamente, haciendo viaje de ida y regreso a Puerto Victoria, donde deberán encontrar la conexión que se hará con las lanchas "Pichis" y "Pizarro". Estos correos harán escala obligada en Contamana y Masisea, recibiendo y entregando en las receptorías de correo, la correspondencia que existiera (Capelo, 1900, p. 101).

Pese a este cambio de itinerario, un hombre de negocios llamado Georg Von Hassel le hace la propuesta al comisionado especial para que el correo sea administrado por un particular, pues según argumentaba, los gastos que se hacían para la conservación y desarrollo de la Vía Central que unía al Departamento de Loreto con Lima, eran muy considerables. Von Hassel ofrece:

que su empresa se encargue de todos los gastos correspondientes a los sueldos de los comandantes, técnicos, operarios, alimentos, etc., estudiar la navegación del Palcazú y Mayro y en caso de necesidad, agregar a la Vía Central un ramal: Puerto Victoria, Palcazú y Mayro, sin exigir ninguna remuneración del gobierno. Establecer en el Pachitea y en el Pichis en el primer año diez puestos o estaciones de leña permanente y una estación principal en la confluencia del Pachitea con el Ucayali. Hacerse cargo del cuidado y conservación de las lanchas que hagan el servicio de correo, a cambio la empresa pide que se le remunere por sus servicios lo que ocasionan las lanchas "Amazonas", "Cahuapanas", "Iquitos" y "Pizarro" al gobierno pero no en dinero sino en terrenos de montaña a razón de cinco soles por hectárea. Será la empresa dueña perpetua de esos terrenos que estarán parcelados de tal manera que pertenezca un lote al gobierno y otro a la empresa, alternados y no siendo ninguno mayor de diez mil hectáreas (Capelo, 1900, pp. 102-104).

El comisionado se vio atraído por la propuesta de Von Hassel, sobre todo por la Vía Central, pues su mejoramiento era algo que le preocupaba por haberlo gestionado. Acepta su propuesta, dejándo copia del contrato en la prefectura y despachándose el original al Ministerio de Fomento para que el gobierno decidiera su completa ejecución.

El vínculo de Capelo con Von Hassel continuará a lo largo de su corto periodo como comisionado especial, teniendo su punto más importante la construcción de un muelle en Iquitos, 
que más adelante será cuestionado por los comerciantes de Loreto al no tener los resultados esperados en la economía local. Para la construcción del muelle se presentaron dos propuestas, el primero era un muelle de madera por la cantidad de siete mil doscientos noventa y cuatro soles a cargo del empresario Teodoro Shuler y el segundo era un muelle metálico por doce mil soles a cargo del empresario Georg Von Hassel. Capelo se inclinó por el segundo y dio una explicación del mismo en sus consideraciones previas:

$2^{\circ}$ Que conforme a este proyecto el muelle deberá tener veinte metros de largo a partir de la orilla del río, descansando por el extremo que debe tocar en el costado del vapor, en una albarenga, y por el extremo situado a la margen del río en un castillo de fierro sobre bases sólidas de albañilería, levantando sobre pilotes convenientemente enclavados hasta el límite necesario para la solidez necesaria del castillo y éste, dispuesto de manera que pueda subir y bajar el punto de apoyo del puente de fierro que forma el muelle a medida que varía el nivel de la albarenga con el de las aguas del río según la estación (Capelo, 1900).

En una publicación sobre el comercio en la región, los comerciantes loretanos mencionaban que las condiciones de este tipo de muelle no estaban acordes con las de un puerto fluvial como el de Iquitos, que iban más bien con los movimientos de:

un puerto fluvial, pues como Iquitos, un muelle provisional como el de Von Hassel, carece de base sólida en qué apoyar uno de sus extremos, el que corresponde al río; y construido el puente a que hoy se llama muelle sobre una albarenga, ha de llegar el momento en que la vaciante sea tan grande, como sucede todos los años, que dicha albarenga baje demasiado de nivel, ocasionando la destrucción del puente, o su deterioro, al menos (Anónimo, 1900).

Por otro lado, Capelo descarta la propuesta de Shuler haciendo mención que se trataba de la «construcción de un local de Aduana, con almacenes de depósito y oficinas, un plano inclinado y un muelle. Obras que conforme a la propuesta se estiman en S/. 261.830, con un desnivel de 4 metros entre la plataforma del muelle y el nivel del río» (Capelo, 1900, pp. 117-119). Estas condiciones no iban acorde a lo que necesitaba Iquitos, pues, según Capelo, el precio era muy alto y en algún momento quedaría inutilizable para el trasbordo de mercadería. Para los comerciantes de Iquitos, la propuesta de Shuler abarcaba obras más sólidas y extensas, y por lo mismo, de mayor duración (Anónimo, 1900). Además, reclamaban que pese a la diferencia de tarifas entre Shuler y Von Hassel, la primera a pesar de ser alta, se trataba de un capital que se quedaría circulando en la plaza por tratarse de un empresario local, mientras que el segundo no ofrecía garantías de hacerse cargo de la inversión que requería el muelle. De todas formas, justo antes de partir de Loreto, Capelo estaba inaugurando el muelle metálico en que había depositado sus esperanzas para modernizar el comercio en Loreto, impulsado por la confianza hacia Von Hassel que se había comprometido a mejorar la Vía Central.

Después de haber despachado las autorizaciones para la construcción del muelle, Capelo se encargó de otro asunto que era de gran importancia en Iquitos, la creación del Colegio de Instrucción Media, teniendo en consideración que el desarrollo alcanzado por la población de Iquitos hacía necesaria la creación del centro de instrucción, a fin de que los jóvenes puedan culminar sus estudios en esa ciudad (Capelo, 1900, p. 130). Además por ser capital del departamento le correspondía tener tal institución, mientras el colegio ya existente en Moyobamba no dejaría de funcionar por desempeñar un papel muy importante en esa ciudad, y que en Iquitos existía el personal idóneo para constituir el cuerpo profesional del establecimiento. 


\section{Administración económica}

También en la Aduana de Iquitos consideró que era indispensable tener una Sección de Estadística de un modo regular y permanente que vigile el movimiento comercial, que comprenda la mesa de confronta, el cuidado y arreglo del archivo. El trabajo estadístico hecho en 1899 había puesto en evidencia las pérdidas ocasionadas al Fisco por la falta de esos servicios. (Capelo, 1900, p. 141). Por todo ello, el 3 de marzo de 1900, por mandato del comisionado especial del gobierno en Loreto, se mandó a crear el cargo de Jefe de Estadística y Mesa de Confronta con el haber de doscientos cincuenta soles mensuales.

En su memoria como comisionado especial, Capelo también deja registrado el establecimiento del estanco de la sal para proteger su exportación en el Huallaga y para abaratar el artículo en Iquitos que se mantenía en alto precio para el año de 1900. Para esto dispone que el Administrador del Impuesto de la Sal, en el departamento de Loreto, regularice la explotación de las salinas del Huallaga, adoptando las medidas necesarias para impedir el ingreso de la sal extranjera, y hacer los arreglos necesarios con las casas importadoras que hayan introducido dicho artículo para que queden garantizados sus intereses y derechos fiscales (Capelo, 1900, p. 152).

En la cuestión del enganche de operarios para la explotación del caucho, también se hizo presente el comisionado especial, atendiendo un informe del subprefecto del Alto Amazonas, disponiendo lo siguiente:

$1^{\circ}$ Que las autoridades políticas provinciales no permitan, bajo responsabilidad, la salida de peones del territorio de su jurisdicción, sin que previamente se preste por los patrones o enganchadores una fianza de firma comercial acreditada, por la cantidad de doscientos soles por cada peón; a fin de garantir el regreso de estos en el tiempo señalado en cada contrato o constatar el fallecimiento del peón garantido si acaso ocurriese, haciéndose efectiva sin más trámite la indicada garantía en caso contrario; y

$2^{\circ}$ Los subprefectos de las provincias darán cuenta mensualmente a la Prefectura del Departamento del movimiento de operarios; alta y baja en el territorio de su jurisdicción para su publicación en el periódico de Iquitos, a fin de que las familias de los interesados puedan hacer ante la prefectura los reclamos a que hubiere lugar (Capelo, 1900, p. 214).

Joaquín Capelo, tras haber estado a cargo de la administración del departamento de Loreto, hasta abril de 1900, se retiró a Lima, en donde al año siguiente sería elegido Senador. Aunque la representación que decidió seguir fue por el departamento de Junín, Capelo mantuvo su preocupación por la situación de Loreto. Ello se vio reflejado cuando, desde el senado, presentó proyectos de ley en 1906 para la delimitación fronteriza de Loreto, la creación del departamento de San Martín y la creación de una Corte Superior de Loreto (Donayre, 2013). Por todo ello, Joaquín Capelo es considerado uno de los personajes de la historia republicana que se preocupó por el porvenir de Loreto y las implicancias que esto traería al futuro de la Amazonía peruana.

\section{Conclusiones}

En las obras más importantes de Joaquín Capelo, en su periodo como Comisionado Especial del Supremo Gobierno en Loreto, se encuentra el impulso que quiso darle a la modernización de la administración de Loreto. No siempre se pudo cumplir a cabalidad lo que dispuso, por ejemplo la cuestión del muelle de Iquitos de la que recibió quejas por parte de los comerciantes después de terminada su gestión, por no haber dado los resultados esperados al comercio. Por otro lado, la regularización de los terrenos de montaña, del correo central, la creación de la sección de Estadística, la protección a los peones en las plantaciones de caucho, etc., contribuyó para que el departamento de Loreto mejorara su situación antes de 1900. 
Asimismo, cuando Capelo tuvo éxito en la gestión del envío de fuerzas para detener el avance de Emilio Vizcarra en Moyobamba, fue consciente de la necesidad de devolver a dicha ciudad la preponderancia que había tenido años atrás, lo cual se logró años después cuando ocupaba un escaño en el Senado.

Loreto experimentó a fines del siglo XIX situaciones tensas por la relación con el Estado peruano, que no se hacían sentir firme en la región, y que cada cierto tiempo debía negociar con los comerciantes, quienes manejaban y sorteaban los cargos públicos en el devenir de sus intereses. Estos intereses muchas veces iban en desmedro de los habitantes indígenas, quienes eran la mano de obra en las haciendas y plantaciones caucheras. Enfrentar ese panorama en esa época, con el gobierno tan lejos, requería prerrogativas especiales en orden y desarrollo para Loreto.

Por tanto, se puede determinar que para Capelo, contribuir a la modernización de Loreto pasaba por atender los problemas que ocurrían dentro de su jurisdicción, a nivel político y administrativo. No todo se cumplió dentro de su gestión, mas puso una de las primeras bases para el desarrollo de Loreto.

\section{Bibliografía}

Aguilar Villanueva, L. (1992). El Estudio de las Políticas Públicas. México D.F.: Miguel Ángel Porrúa.

Archivo General de la Nación, Archivo Republicano, Fomento. Expediente del Comisionado Especial del Supremo Gobierno en el Departamento de Loreto. Rafael Quirós. Iquitos, 14 de enero de 1898. n57, p.1-2.

Anónimo (1900). El comercio de Loreto. Representación del comercio de Loreto sobre las tarifas de carga, descarga y muellaje, impuestas por el doctor Joaquín Capelo, comisionado especial del Supremo Gobierno. Lima: Imprenta Comercial de H. La Rosa \& Ca.

Barclay, F. (2009). El Estado Federal de Loreto, 1896. Centralismo, descentralización y federalismo en el Perú, a fines del siglo XIX. Lima: Instituto Francés de Estudios Andinos; Centro Bartolomé de las Casas.

Capelo, J. (1900). Registro Oficial del Departamento de Loreto. Administración del Comisionado Especial del Supremo Gobierno Señor Dr. Joaquin Capelo. Lima: Imprenta de la Escuela de Ingenieros - J. Mesinas.

Donayre, J. (2013). Capelo, un fundador de la selva. Obtenido de Miscelánea. Recuperado en 20 de junio de 2018 de http://miscelanea-rafo.blogspot.com/2013/07/capelo-un-fundador-de-la-selva.html

Espinoza, W. (2016). Loreto. Departamento y Región (San Martín - Ucayali) 1846 - 2000. Lima: Fondo Editorial de Universidad Nacional Mayor de San Marcos.

Habermas, J. (2002). La modernidad, un proyecto incompleto. En Foster, H. (Ed.), La posmodernidad (pp. 19-36). Barcelona: Kairós.

Laski, H. (1960). Introducción a la política. Buenos Aires: Siglo XX.

López Soria, J. I. (2007). Adiós a Mariátegui. Pensar el Perú en perspectiva postmoderna. Lima: Fondo Editorial del Congreso.

Quiñones Tinoco, L. (2012). Construir y Modernizar: el Ministerio de Fomento (1896-1930). Lima: Editorial Universitaria. UNI.

Ruiz, A. (1994). Psiquiatras y locos: entre la modernización contra los andes y el nuevo proyecto de modernidad. Perú 1850-1930. Lima: Instituto Pasado y Presente.

Santos Graneros, F y Barclay, F. (2002). La frontera domesticada. Historia económica y social de Loreto 18502000. Lima: Fondo Editorial Pontificia Universidad Católica del Perú. 